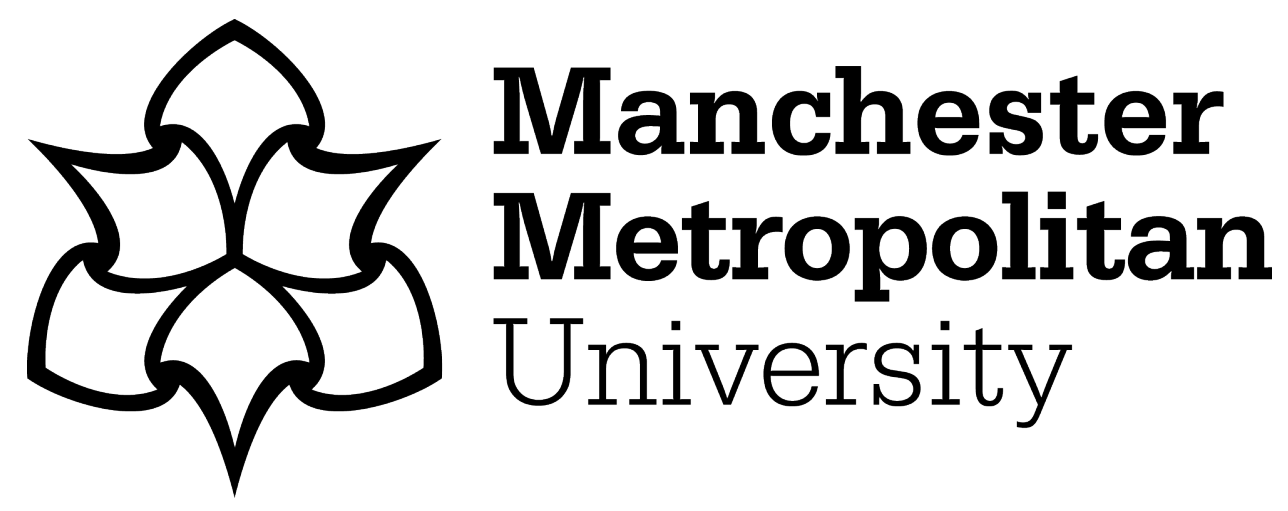

McMichael, Celia, Nunn, Caitlin, Gifford, Sandra and Correa-Velez, Ignacio (2017) Return visits and belonging to countries of origin among young people from refugee backgrounds. Global Networks, 17 (3). pp. 382-399. ISSN $1470-2266$

Downloaded from: https://e-space.mmu.ac.uk/621955/

Version: Accepted Version

Publisher: Wiley

DOI: https://doi.org/10.1111/glob.12147

Please cite the published version 
McMichael, C., Nunn, C., Gifford, S.M. and Correa-Velez, I. (2016). 'Return visits and belonging to countries of origin among young people from refugee backgrounds' Global Networks. doi: 10.1111/glob.12149.

\title{
RETURN VISITS AND BELONGING TO COUNTRIES OF ORIGIN AMONG YOUNG PEOPLE FROM REFUGEE BACKGROUNDS
}

Celia McMichael, Caitlin Nunn, Sandra M. Gifford and Ignacio Correa-Velez

\begin{abstract}
In this paper we explore the phenomenon of return visits by resettled refugee-background young people to their personal and/or ancestral countries of origin. We draw on qualitative data from a longitudinal study of young people with refugee backgrounds who resettled in Australia, all of whom fled their country of origin at an early age, and many of whom were born or lived for protracted periods in countries of asylum. We demonstrate that return visits are not simply a homecoming; young people's narratives reflect ambivalent relations to their homeland that are experienced across multiple domains of belonging. Accounts of return visits refer to three core domains of belonging: practical national belonging, family connection, and attachment to material places. We argue that for these refugee background youth, a return visit provides a valued opportunity to negotiate and develop connections to homelands, though not necessarily an unambiguous opportunity to belong.
\end{abstract}

Key words TRANSNATIONALISM, TRANSNATIONAL MIGRANTS, BELONGING, YOUTH, RETURN VISITS, REFUGEES

\section{INTRODUCTION}

In this paper, we explore how resettled young people with refugee backgrounds living in Australia experience return visits to personal and/or ancestral homelands. The paper contributes to the growing body of research into the transnational and return experiences of refugees (Binaisa 2011). However, the transnational links of refugee background youth to their personal and/or ancestral country of origin have received limited attention, and to our knowledge there is no literature that focuses on return visits among refugee-background young people. This paper takes as an analytical framework three experiential domains of the 
homeland - (i) practical national belonging, (ii) family networks, and (iii) attachment to material places - through which we explore young people's narratives of return visits. We demonstrate how return visits provide a valued opportunity to renew and negotiate connections to personal and/or ancestral homelands, though not necessarily an unambiguous opportunity to belong.

Return visits describe trips made by members of diaspora communities who have social and cultural ties to a destination, either by birth, descent, or first-hand (non-tourist) experience (Duval 2004; Sagmo 2014). While they function to link social fields and develop transnational identities, their immediate purpose is generally for tourism, leisure, seeing family or learning about homeland culture (Kibria 2002; Vathi and King 2011). Researchers have examined migrant return visits to countries of origin, both as a stand-alone experience and as a precursor to long-term return (Baldassar 2001; Binaisa 2011; de Bree, Davids and de Haas 2010; Duval 2003; King et al. 2011; Oeppen 2013; Vathi and King 2011).

Refugee return visits represent a distinct experience within the broader phenomenon of migrant return visits (Al-Ali et al. 2001). Among resettled refugees, there are low rates of permanent return to countries of origin, even when socio-political conditions improve (Richardson et al. 2004; Hugo 2011; Khoo 2012; Oxfeld and Long 2004). Although the practice is widespread, there are no reliable figures indicating rates of return visits among refugees resettled in Australia or elsewhere. When refugees return to their home country following forced displacement, it is often to societies and places that have been 'transformed in the interim through war, political upheaval or economic crisis' (Jeffery and Murison 2011: 132). Wartime conditions include rapid social change, threats to security and life, separation from and death of family members, persecution, economic hardship, hunger, damage to physical spaces, and displacement (Farwell 2001). Oeppen, in her study of adult Afghan refugees living in the USA writes that return visits led to disappointment and sadness as people noted the differences between the Afghanistan they left and the one to which they returned (2012: 267). Iaria (2013) highlights the accounts of adult Iraqi refugees who had been living in Syria and Jordan, and who returned to a country affected by 
violence, food and water insecurity, inadequate infrastructure, poor living conditions, and limited livelihood opportunities.

While Duval writes that "the returning visitor has intimate social and cultural knowledge of the destination that can only come from first-hand experience" (2004:51), this cannot be assumed for refugee-background young people. These youth may have been forcibly displaced and resettled at an early age or may have been born or lived in countries of asylum for extended periods. Accordingly, young refugees potentially have limited or no first-hand experience of a homeland to which they make a return visit. This is an important contextual framework that shapes young people's experience of return and their sense of belonging. And yet the lives of refugees often have continuity in terms of history, ancestry, ethnicity and language, culture, personal biographies, and ongoing family connections to homelands. It is against this background that refugee return visits occur, with homelands representing a site of significant social and political upheaval, a potentially unfamiliar place for young people, and yet sites to which they have enduring ties.

Studies have underscored the social, psychological, economic and political complexities of return visits and repatriation among refugees (Barnes 2001; Bascom 2005; Carruthers 2002; Farwell 2001; Muggeridge and Doná 2006; Oxfeld and Long 2004). Return visits and repatriation rarely represent a homecoming to a site of belonging. Only a few studies have focused on return visits (as opposed to repatriation) among resettled refugees (Barnes 2001; Muggeridge and Doná 2006). Barnes (2001) conducted research with refugees from Vietnam (aged in their thirties and forties) who had lived in Australia for 15 to 20 years, and argued that return visits served as a reality check against an idealised homeland and led to the realisation that ties to their country had forever changed. Muggeridge and Doná (2006) examined experiences of return visit among 15 people with refugee backgrounds (aged 2750 years) who had settled in the United Kingdom. They indicated that return visits acted as a catalyst to re-examine lives and key decisions in a site of settlement and to renew engagement with countries of origin, experiences which supported an end to feelings of uncertainty about their futures. A much larger number of studies have focused on postconflict repatriation of refugees (Allen and Morsink 1994; Arowolo 2000; Bascom 2005; Black 2002; Cornish, Peltzer and MacLachlan 1999; Cuny and Stein 1990; Farwell 2001; Iaria 
2013; Oxfeld and Long 2004; Rousseau, Morales and Foxen 2001; Saito and Kantor 2010; Stefansson 2006). The large majority of these studies of refugee return visits and repatriation have concentrated on both first and second-generation adult refugees. A few document the experiences of young refugees, but only in the context of repatriation. For example, in her study of Eritrean young people returning permanently to Sudan following forced displacement, Farwell (2001) argued that young refugees struggle to manage familial, social and political expectations, including cultural norms of early marriage and national service obligations. Rousseau et al. (2001) discussed how young Guatemalan refugees experience the collective project of going home following extended exile in Mexico. They examined strategies for making sense of Guatemala's past, with some returning refugees denouncing the trauma of war and others using silence as a means of persevering in the face of traumatic histories. There are no published studies of return visits, as opposed to repatriation, among young resettled refugees.

Return visits have been overshadowed by analysis of other forms of migrant transnational connection and engagement (Vathi and King 2011: 505), including communication technologies, remittances, diasporic networks, and consumption of homeland media (Basch et al. 1994; Fallov, Jørgensen and Knudsen 2013; Gifford and Wilding 2013; Gustafson 2005; Lee 2011; Vertovec 2009). Yet far from being superseded by deterritorialised connection to homelands, situated experiences during return can both enable and challenge belonging to homelands (Baldassar 2001; King, Christou and Teerling 2011; Wimmer and Glick Schiller 2002). Belonging is a contested and multi-layered term (Yuval-Davis 2006). For migrants, belonging is generated through personal histories and memories, ancestral connections, social ties with families and friends, culture, language, economic engagement, length of residence, and connections to place and people (Antonsich 2010; Fallov et al. 2013).

Belonging to homeland is particularly vexed for refugees given their histories of persecution, flight, exile and settlement, as evident in ongoing tensions between definitions of homeland pertaining to physical places and those referring to symbolic and imagined spaces (Al-Ali and Koser 2002).

In this paper, we examine narratives of return visits and belonging through the analytical framework of practical national belonging, family connections, and attachment to place. 
This framework emerged from thematic analysis of young people's narratives of return visits. Practical national belonging refers to everyday acceptance or non-acceptance of particular people as a subject of belonging by the dominant national community (Carruthers 2002; Hage 1998: 52; Skey 2010). It is negotiated through a process of embodying and performing sanctioned social and physical characteristics and behaviours, so that those with 'national cultural capital' make judgements about the identity status of others (Hage 1998). Family connections refer to the more emotional and intimate dimensions of belonging and attachment to home as generated through engagement with family (Yuval-Davis 2011). Family is often a locus for understanding and expressing diverse desires for human connectedness and belonging. While family belonging is not necessarily linked to particular geographies, places often become meaningful sites of belonging because of intimate and familial relationships with people living there (Gustafson 2001: 9). Attachment to material places refers to the sense of being at home in and belonging to place (Antonsich 2010: 647). Belonging to material places is generated through: knowledge of how to behave in material spaces (Fortier 2000); sensory and bodily familiarity with natural and built environments (Friedmann 2002; Tilley 1994); and familiarity with meanings ascribed to landscapes and places via habitual routines (Leach 2002). Yet the centrality of material and bodily experience to encounters with places is largely absent from examination of migrant belonging.

This paper, then, focuses on return visits by resettled refugee-background young people and their experiences of personal and/or ancestral homelands across multiple sites of belonging. The findings are structured in two sections. In the first section we discuss young people's desires and reticence around return visits, highlighting the varied relationships that refugeebackground youth have to their homelands from a site of settlement. In the second section we describe experiences of return visits in relation to three domains of belonging (discussed above): we discuss young people's negotiation of practical national belonging to the wider national community, their connections to family networks often after many years of absence, and their familiarity with and embodied responses to natural and built environments. We illustrate that for these refugee-background young people return visits 
do not represent an unambiguous home-coming, and we examine the intersecting domains through which connection and belonging to homelands is negotiated and experienced.

\section{METHODS}

The findings in this paper are derived from 51 in-depth interviews with refugee background youth living in Melbourne. Participants were part of a larger cohort of resettled refugee youth who participated in a longitudinal study of settlement and wellbeing (Gifford et al. 2007; Gifford et al. 2009). In 2004, 120 young people (55 female, 65 male) were recruited through English Language Schools that provide intensive language education to newly arrived students. All participants entered Australia via the Offshore Humanitarian Settlement Program, through which they are recognised as having refugee status and granted permanent residence in Australia and a pathway to citizenship after four years of residency (increased from two years in 2010). Visual, qualitative and quantitative data were collected over five waves between 2004 and 2012-13. At first interview they ranged in age from 11 to 19 years and their average length of time in Australia was 6 months. They were born in 12 different countries, and sampling reflected the main regions of origin of refugee arrivals at the time. Only one-third of the cohort were resettled in Australia with both parents, and many had parents, siblings and other close family members living in the country or region of origin, or elsewhere in the diaspora (McMichael, Gifford and CorreaVelez 2011).

During 2012-13, a final (fifth) wave of data collection was conducted, eight to nine years after initial interview. It focused on longer-term outcomes and experiences of settlement and transitions into early adulthood. Research methods included an in-depth interview and a short questionnaire. Interviews were conducted in English, digitally recorded, and transcribed verbatim. 51 members of the original cohort ( 25 females, 26 males) were able to be contacted and agreed to participate. Thirty-three originated from Africa (Sudan ${ }^{1}$, Ethiopia, Eritrea), 16 from the Middle East (Afghanistan, Iraq), and two from Europe (Croatian-born Serbs). Participants were broadly representative of the original cohort, with no statistically significant differences in terms of gender, region of birth, or years of schooling prior to resettlement (McMichael et al. 2015). At the time of interview, they were 6 
aged between 18 and 27 years. Interviews were analysed thematically (Patton 2015), using NVivo software. A coding framework developed for analysis of qualitative data collected in the first four waves of the study was further refined based on inductive analysis of the wave five interview data. The themes discussed below emerged, in the fifth wave interviews, as common aspects of return visits as identified by participants. The structure and size of the cohort did not support analysis of differential experiences of return visits based on, for example, gender, country of birth, or resettlement experience. Participants are referred to using pseudonyms; their gender, self-ascribed cultural background, country of birth, and age at time of interview are provided (within text or following quotations).

\section{FINDINGS}

\section{IMAGINING RETURN TO A COUNTRY OF ORIGIN}

Eight to 9 years after arrival in Australia, participants overwhelmingly imagined and planned their futures as being in Australia (Nunn et al. 2014). Yet affective connection to homeland was widely expressed using possessive pronouns - 'my home', 'my people', 'my blood' or 'my country' - reflecting a strong sense of connection to their personal and/or ancestral countries of origin. Of the 51 participants, 17 had made at least one return visit to their homeland, 19 had not returned but were hoping to in the future, and 15 did not intend to make a return visit.

Among those 19 young people who had not returned but indicated they would like to, key reasons for anticipated return visits included: to see relatives, to contribute to their country's development through work and investment, to pursue employment opportunities, to revisit places and homes, to reconnect with friends, and - for a few - to visit a homeland in which they had never lived. Sarah, for example, imagined return to Sudan as an opportunity to reconnect with her country of birth and to help local people:

I've never really seen Sudan, I just hear stories about it . . . I always like thought of trying to open up a community hospital or something. 'Cause it's so expensive, like, to go to a good hospital ... Just do something to help out the community. (Female, Sudanese, born Sudan, aged 22) 
Fifteen young people, however, said they did not intend to make a return visit. For many, this was because their family and friendship networks were disrupted or lost. Fahim was born in Afghanistan, and identified as Afghani, but lived in Pakistan with his family for 12 years. Fahim came to Australia as a refugee with his parents and siblings aged 13 years. His mother had a photograph of relatives from Afghanistan hanging on her wall, but his family is now dispersed around the world and they have lost contact with people in Afghanistan. When aged 22, Fahim had no plans to visit Afghanistan or Pakistan, saying 'you definitely feel like at home [in Australia]. You don't miss your country'. Mariam and her family were from Iraq, and she identified as Chaldean. She was resettled in Australia with her parents and siblings, after three years of living in Syria. Several years post arrival, Mariam told us that she only had an uncle and aunt who remain in northern Iraq which made a return visit 'pointless':

They all left. So like going there would be kind of pointless but then you'd see your old - where you lived and the streets, it just fills that feeling. Yeah. But nothing more. (Chaldean, born Iraq, aged 19)

Others reflected on how their countries of origin were still sites of significant social and political disruption, and ongoing security concerns precluded return visits. Talking about her family in South Sudan, Yar said. 'North government they go and kill them ... It's still not safe there. There's no security' (Dinka, born Sudan, aged 25). Several commented that their countries remained too dangerous to visit: 'Africa is dangerous' (Aciek, female, Nuer, born Sudan, aged 22); 'There's still more fights' (Matet, male, Dinka, born Sudan, aged 23); 'Now in my country it's not gonna be safer than here, never... If we go there we can get killed, what's the point? People they get killed easily there' (Sesa, male, Assyrian Chaldean, born Iraq, aged 23). None of the eleven Chaldean and Assyrian Iraqis had returned to Iraq nor planned to do so. This is indicative of the challenge of contemplating return and sustaining ties where instability continues and minority groups continue to be persecuted, as are these Iraqi Christians (Iaria 2013). 
Three participants (of the 15 who did not intend to return) said they were not interested to make a return visit because they did not feel a sense of connection to their homelands. Haga fled Sudan aged 12 years and lived in Egypt for three years before resettlement in Australia with her parents and siblings. Contemplating return to Sudan, Haga said, 'I don't think I'm gonna to fit in. I don't know the environment. Because I never grew up there... right now I wouldn't want to go there' (Jurchol, born Sudan, aged 25). Assadullah left Afghanistan with his parents and siblings and lived most of his early years in Pakistan; he commented 'I was born there but . . it hasn't given me anything' (Afghani, born Afghanistan, aged 20). Djuro is Croatian-born and identified as having Serbian ethnicity. He and his family lived in Serbia for 12 years prior to their settlement. He arrived in Australia aged 14 years. When aged 23, Djuro said there was nothing of interest in his family's homeland, Croatia, and that he preferred to remain in Australia:

You're not gonna visit Croatia, there's nothing to do, nothing to see there. . I like it here better now because I don't live over there now anymore.

Accounts such as these indicate that homelands are not sites to which some participants feel sufficient connection to warrant a return visit. For refugees, as compared to migrants more broadly, capacity and desire to return to their countries of origin are shaped by the social, political and economic upheaval associated with war, displacement and resettlement. This reality is magnified for resettled young people with refugee backgrounds, many of whom have little memory of their homeland due to forced displacement at a young age.

\section{RETURN VISITS}

Eight to nine years post-arrival in Australia, 17 of the 51 participants had made a return visit to their countries or regions of origin including Ethiopia, Sudan, Croatia and Afghanistan. The past and current conditions of their homelands differ substantially, as do their experiences of displacement and resettlement: what is shared is that their displacement was forced, their homelands represent dynamic and changing socio-political landscapes, and all participants were young at the point of resettlement.

Six of the participants made return visits by themselves, ten returned with family members (including parents, aunts, siblings and - in one instance - a young child), and one returned 9 
with friends. Six participants described return visits as personally instigated (e.g. 'I wanted to go at least to be in front of them, to be together, be happy with family'); eleven described decisions to return as being made in consultation with family (e.g. 'my dad actually encouraged me to go. He was like I'm starting to forget back there, and the relatives'). Stated reasons for return included tourism, to see family members who had become unwell, family reunion, to attend weddings, to connect with their homeland, for marriage, and (more poetically) 'to see it with my own eyes'. At the time of return participants were aged in their mid-late teens and early twenties. The length of return visit ranged from a few weeks to seven months. Given the histories of conflict and causes of refugee-hood, return visits were typically possible only after a change of political circumstances.

Although the young people who made return visits had different pre- and post-migration experiences, during their return visits they all confronted the tensions and convergences between the imagination and the reality of their homeland (Muggeridge and Doná 2006). Importantly, their histories and pre-existing connections to their personal and/or ancestral homeland were extremely varied. While some had clear memories of their homeland, others fled before lasting memories were formed, and a few were born and lived their early years in countries of asylum. Participants also had diverse personal, family and settlement experiences in Australia, including in relation to education and employment pathways and social inclusion; these experiences may have shaped attitudes toward and experiences of return visits, yet potential causal connections are both murky and complex. Nonetheless formal citizenship in Australia is acknowledged as an important aspect of settlement in that it enables secure international mobility, and specifically the ability to visit family and homelands (Nunn et al. 2016). Beyond this, young people's narratives of imagined return visits - whether desire, indifference or reticence - speak more to their memories, imaginations and understanding of their homelands. Experiences of belonging were multilayered, with the politics of social inclusion/exclusion and affective experiences of connection to homeland being played out via: practical national belonging to the wider community; family connections; and connection to material place.

\section{Practical national belonging}


For a few, return visits engendered a new-found sense of connection and belonging to the national community in their homelands. They said that upon return they looked like everyone else and they were happy to be amidst their 'people'. Senay identified as Eritrean, but was born and lived in Sudan as a refugee with his family throughout his early childhood. He was resettled in Australia, aged 12 years, and lived with his father and siblings. When we interviewed him eight years after arrival in Australia, aged twenty, he explained 'I've been calling Australia home now for, you know, the past eight years almost but it's not home really'. He recalled his return to Eritrea, when he was 15 years old, where he had travelled to attend his father's wedding. His account highlighted a sense of incredulity and joy at being amidst his people and an overwhelming sense of personal connection to Eritrea and its people:

To actually be in the country [Eritrea] that you know, that's where I'm actually from, that's where my people are, that's - it was, it was a feeling that l'd never felt before, and it was good. It was, yeah, I mean, just to see your people everywhere you go, it's just your people everywhere, it's amazing, and it's a good feeling. (Male, Eritrean, born Sudan, aged 20)

Yet for others, their accounts of return visits highlighted more complex processes of seeking and granting belonging (Carruthers 2002). Their sense of practical national belonging acceptance or non-acceptance as a subject of belonging by the dominant national community - was negotiated and often precarious. These young people returned to their countries of origin after having lived for many years in Australia. Akok, a Sudanese male, fled Sudan with members of his family and lived in Egypt for four years before being resettled in Australia. He arrived in Australia aged 16 years and lived with his aunt, uncle and siblings. Several years later, when aged 25 , he returned to South Sudan to visit his mother who he had not seen since he was seven. He spoke of the unnerving experience of queuing in the 'foreigner' line upon arrival at the airport when he arrived in Juba, South Sudan: 'well, legally they treated me as a foreigner at the airport, and [I] have to stay in the foreigner [queue]'.

Beyond this sense of foreignness, as foregrounded via legal recognition of Australian citizenship, practical national belonging was negotiated via everyday activities. Often-times 11 
limited knowledge of local language, clothing and behaviours set young people apart as national others (see also Carruthers 2002). Return visits raised complex questions as to whether youth belonged. Some were not recognised as legitimate local subjects. Fikre returned to Ethiopia with his mother to visit his parents' ancestral homeland and 'to see how it was ... meet families that l've never seen before'. He was born and had lived in Sudan as a refugee for 12 years, and this return was his first physical encounter with Ethiopia, a country he described as 'a place that I never seen before'. Fikre said: I went to this club, and we were dancing and everything, sat down just drinking at the bar and my cousin told, I told him not to tell anyone, anyone that I'm from overseas, I'm from here. The guy just right away he open his big mouth to these nice girls: "Hey my friend is from overseas, from Australia, this and that". They came running straight away. (Tigray/Ethiopian, born Sudan, aged 21)

Fikre emphasised that he was viewed as coming from elsewhere: while his life and experience in Australia sparked interest ('people love you there if you're from Australia'), it also meant he was not accepted as a subject of local/national belonging. Similar experiences were described by several others: 'you can't walk by yourself, you know. They treat you like a princess or something like that, 'cause yeah you come from a big country' (Nyandeng, female, Dinka, born Sudan, aged 24). Accounts such as these provide a heightened sense of being defined by their residence and everyday lives in Australia, rather than connection to personal and/or ancestral homelands.

Many highlighted self-awareness of how they appeared and acted. Having lived a substantial period of their adolescence and early adult life in Australia has shaped the way they dress, talk (with varying levels of fluency in local languages), eat, perceive and respond to homeland conditions. They described a sense of otherness that is marked by their unfamiliarity with the rhythm and habits of life, everyday interpersonal dynamics, modes and means of communication, and self-presentation. Nanjuor said she was regarded as a wealthy visitor from another country:

Like even though I dressed up normal just like them, 'cause I didn't want any special treatment or whatever, but they notice this girl is coming from Australia ... They 
thought that I had a lot of money because I'm coming from Australia and all that ... Well, I had to give some money because some of them were really, like the way they lived and everything was just hard. (Jur/Sudanese, born Sudan, aged 22)

A few highlighted that local family, friends and community had recognised their local language skills, behaviours and cultural capacities; this supported a sense of belonging to homelands. Further, they were proud of the ability to perform and behave appropriately in local settings. Nyandeng is a young woman with Dinka cultural background who was born in Sudan. She lived most of her early years in Kenya. Nyandeng was resettled in Australia aged 15 and lived with her mother and siblings. She returned to South Sudan aged 19 with her mother and siblings, and recalled how she was praised for having remembered her culture after performing a traditional dance in her village:

People was dancing. They didn't expect me so I'm gonna dance, 'cause I'm a city girl. I put my make up, I wearing high heels. ... When they was dancing I ran, I danced. They go, "Oh my gosh, she know how to dance! She come from city!" you know? So my uncle said, "See, you didn't forget your culture; it's good." (Dinka, born Sudan, aged 24)

As these accounts indicate, returning young people are not readily accepted as subjects of national belonging. These youth have differing competency and familiarity with local languages and practices, and different experiences of acceptance and non-acceptance, yet all spoke of processes of performing and negotiating practical national belonging.

\section{Family connections}

While young people are not necessarily granted or feel a sense of practical national belonging, they have a strong claim on connection to extended families. Family relations can be maintained transnationally (Baldassar 2007), but face-to-face family encounters were an important reason for return visits and a central domain of attachment and connection.

Most visits were motivated by a desire to meet and reconnect with family. As Aisha, a young South Sudanese woman, stated, 'I only wanted to see my blood, that's what I want, nothing 
more' (Sudanese, born Sudan, aged 25). Some described a renewed sense of belonging to family. Describing a return visit to Eritrea for a family wedding, Senay said:

We had all these family members to meet. Well, especially for me to meet, and for my dad to catch up with, and yeah, so it was very full on, it was intense. I think the most I slept was like six hours while I was there ... all these people, you feel like you should be there with them because they're your family. . . I don't think it's natural to be away from your family. (Male, Eritrean, born Sudan, aged 20)

Family encounters, however, were shaped by the passing of time. The majority of participants fled with one or more family members when they were young, and some had not retained strong memories of extended family. Others could not recognise family members who had since grown up and now had 'different faces'. Aisha described how she left her village in Sudan with her family when she was six years old, displaced first to Khartoum and then later fleeing to Egypt. Recalling her visit to South Sudan with her young child, she said:

Oh my god, I was lost! Because it's been a long, long, long . . . I don't even know which one is my uncle, which one is my brother - my brothers look different, my sisters look different. It's something like I don't even know them. (Sudanese, born Sudan, aged 25)

While some young people had retained or developed capacity to talk in local languages, others found the language barriers upon return isolating. Fikre grew up in Sudan, and had learnt rudimentary Tigrinya through playing pool with his Ethiopian friends in Australia. Upon return to Ethiopia to meet with family, he was not fluent in the local language:

They speak Tigrinya to me, I mean, hard core Tigrinya. Like assuming that I speak a lot . . . I actually understood most of what they were saying but like we still find it hard to communicate with them, you know what I'm trying to say. The words are really hard to come out. (Tigray/Ethiopian, born Sudan, aged 21) 
For a few, a return visit was an opportunity to remake family ties. Nyandeng returned to Sudan with her mother and siblings to meet her father who went missing during the Second Sudanese Civil War. Since coming to Australia, her mother phoned their village regularly to ask if he had been located, and after a few years, Nyandeng's uncle phoned to say her father had been found. Nyandeng said, 'we were so happy 'cause we didn't know all these years, where - maybe they kill him for that war'. She described her return visit to Sudan to see her father:

He was living with his brother and sister... that's our first time to go to village ... It was difficult, different, but, yeah, we can't do anything about it. Life is hard there. There's no light, there's no good food, there's no good water. But, yeah, it's our own country, and my dad is there, so we have to go and see him. (Dinka, born Sudan, aged 24)

This trip provided an important opportunity to form connections to her father, her father's four wives, and his extended family. Four years later, Nyandeng returned again to South Sudan (post-independence) to see her father, recalling 'I went there and saw some days with my dad, with my cousin. It was very nice travelling around'.

Family connections, however, were not always readily established or re-established. For some, the reality of encounters did not match expectations. Akok left his village in Sudan aged seven and moved to Khartoum and later to Egypt. He came to Australia with his uncle and aunt and their children. Akok re-established connection with his mother a few years after arrival, and wanted to return to visit her. He said, 'I started getting contact with her. So I've talked to her a couple of times and decided to go back'. Although 'it was great meeting her for the first time in years', Akok found the visit awkward:

Things feel a bit awkward, I would say. Yeah. I didn't really have much to talk about. We didn't really have much to talk about. So yeah, it's just a short conversation really. . . I mean, even until now, I'm still doing the best I could to, you know, stay as much closer to her as I could. But again, you know, we don't really have much things to talk about. (Male, Sudanese, born Sudan, aged 25) 
Others recounted similar experiences, also describing interactions with family as 'awkward', and saying that some of their family were 'not welcoming'. Indeed, for Senay, the very experience of being amidst a wider family network was unfamiliar as he was 'used to not having a family' due to extended family separation. Participants were making return visits after many years of physical absence, and family networks emerged as a central domain for expressing experiences of connection and belonging to their homelands. Despite clear ancestral and familial connection to family networks in the homeland, belonging in this domain was still negotiated upon return.

\section{Attachment to material places}

Belonging is also experienced in terms of connection and familiarity with material places (Antonsich 2010; Fortier 2000; Rishbeth and Powell 2013). For these returning young people, material places were variously: not as they remembered; transformed; or familiar yet no longer comfortable and secure sites. For some, given their young age at displacement, homelands were sites they had largely forgotten:

Yeah all new, I can't remember. You know, how can you remember when you young? It's different... It's a big difference now, they change, they putting house, everything. (Bekele, male, Ethiopian, born Ethiopia, aged 25)

A few 'returned' to places they had never lived. Senay described seeing Eritrea, his ancestral homeland, for the first time. Born in Sudan, he had known very little about Eritrea and felt happy to see the country, describing it as more 'beautiful' than he expected:

'The city's pretty modern, I mean, cafes all over, there's cinemas, there's nice restaurants, and quality food, nice streets, clubs'. (Male, Eritrean, born Sudan, aged 20)

A few people reflected that they had become accustomed to Australia and, in comparison, material environments now appeared unfamiliar or dangerous. As Nanjuor said, in describing her visit to Sudan, "I got used to here - so when I went back there it was totally 
different and hard'. Zoran, a Croatian-born Serb, was struck by the quietness and lack of people in Croatia, in contrast to Australia:

I can't imagine myself living there. It's just, you know, it's quiet and nice but it's dead. It's like, you know. . . . Maybe because I'm used to, like, in a big city and stuff. But you know, I can't imagine myself living there, in Croatia now. (Male, Serbian, born Croatia, aged 23)

Many participants described the material realities of their countries of origin as 'crowded' or 'empty', 'noisy' or 'quiet',' busy' or 'dead', 'dirty', 'difficult' and 'hard'.

Among those who retained memories of their homeland, visible changes were a point of discussion and they remarked that 'everything change, life change, everything' (Idris, female, Ethiopian, born Ethiopia, aged 23). While they knew that political, economic and social changes had occurred, personal experience of these changes was confronting. Some described the visible evidence of war. For a few, having fled when their countries were experiencing socio-political turmoil and conflict, subsequent development of infrastructure and living standard was surprising. Arif, a young man from Afghanistan, visited Kabul when he was 21 years old and said that the city was not as he remembered:

In the city, I can't recognise it. It's like a different city. . Old time you can see clearly. Now it's very difficult because too much stuff being built and business and everything. It's very hard now. (Tajik/Afghani, born Afghanistan, aged 25)

Aisha, aged 25, commented on the development in South Sudan; when she left there was no toilet, electricity or running water in her home and upon return there was a toilet, electricity generator, tap water piped into the house and mobile phones. She exclaimed: 'I was like, wow you guys have developed'.

Finally, four young people described uncomfortable embodied responses to material environments, including climate, foods, built environments and pathogens (see also May 2011; Rishbeth and Powell 2013). Some narratives of return highlighted experiences of discomfort: the food was too spicy, the weather too hot, and the living conditions contributed to poor health. Aisha reported that she and her young child felt unwell because South Sudan no longer 'matched' them. She described how her son became ill because 'he doesn't belong to that country'. Nyandeng stayed in her family's village in Sudan for one 
month, and said that 'it was too much for me', when describing the poor sanitation, lack of clean drinking water, traditional food, illness, rain, heat, and mosquitos. She became sick with malaria. Akok returned to Sudan and recalled that 'the weather wasn't good for me' and he became sick:

The environment wasn't really good with me . . I been hot, and hot all the time. And just within three weeks I lost like nine kilos or something. I was really skinny. . I completely lost appetite of eating. The heat, it's just, I'm not used to it. Yeah, so I find it really difficult. (Sudanese, born Sudan, aged 25)

These accounts of sickness, physical discomfort and lack of familiarity with foods, climate and material environments bring to the fore young people's embodied experiences that destabilise a sense of belonging. As May writes, 'it is from this lack of fit that a sense of unease, of not belonging, emerges' (2011: 370). For these young people, their narratives of return highlighted ambiguous belonging to material places, particularly their lack of familiarity with and embodied responses to natural and built environments.

\section{DISCUSSION AND CONCLUSION}

Return visits have diverse impacts on people's perceptions and experiences of homeland (Vathi and King 2011). In this study, many - though not all - of the refugee-background young people longed to visit their countries of origin. Return visits, however, were not experienced as unambiguous homecomings to countries and communities that had been imagined (in their words) as 'my home' and 'my people'. Participants' narratives of return illuminated different domains of belonging - practical national belonging, family connections, and attachment to material spaces - and experiences of these domains were negotiated and differently valued.

Return visits were permeated with a sense of ambivalent belonging to personal and/or ancestral homelands. Young people spoke of, for example, connecting to family but not feeling or being granted a sense of belonging to the wider national community, feeling pride at their capacity to converse in local languages but finding the natural and built environment unfamiliar and difficult, or enjoying being amidst 'their people' but having 
awkward connections with relatives. Their narratives illustrated the dialogic nature of homeland belonging, involving seeking and granting. At times they personally felt a sense of connection but were made to feel other; at other times they were welcomed where they did not feel they belonged; and there were times where belonging was mutually acknowledged or denied (Carruthers 2002; Kumsa 2006).

There is a widespread assumption that feeling out of place is undesirable, as people feel excluded from place and people, and their 'ontological security' is shaken (Giddens 1990). But a feeling of not belonging need not always be negative (May 2011: 373). Not belonging can awaken reflexivity, allow us to 'see what could be', and support new narratives of identity (May 2011: 373). For many young people, a return visit revealed that 'homelands', while remaining central to their identities, did not necessarily constitute a comfortable site of belonging or 'home'. Yet narratives of return visits indicated they were valued experiences that acted as a catalyst for ongoing connection and attachment, if not unequivocal belonging, to homeland. Recalling his first visit to Eritrea, when aged 15, Senay said:

I was born a refugee. I was born in Sudan as a refugee, so that in itself, that in itself is not yeah, it's not ideal . . but look it's good to have something, it's good to have a heritage and to know it. (Eritrean, born Sudan, aged 20)

While existing studies of return visits and return migration focus predominantly on adult first generation migrants and refugees (Baldassar 2001; Barnes 2001; Duval 2003), the experiences discussed here are of young people with refugee backgrounds who were resettled in Australia during childhood and early adolescence. Aspects of return visits among young people with refugee backgrounds echo those of adult refugees who visit or are repatriated to their countries of origin (c.f. Barnes 2001; laria 2013; Muggeridge and Doná 2006; Oeppen 2013), including the gaps between imagination and reality, changed social and familial relationships, and recognition of the ongoing challenges for local people's everyday lives. But the experience of return visits for these young people were strongly influenced and, perhaps, heightened by their young age at displacement and resettlement. All fled their countries at an early age, some were born in countries of asylum, and all were 19 
resettled in Australia in their early to late teens. Return visits represented an opportunity to engage with homelands that were not only changed through the social, political and material impacts of war, but which may also have been personally unfamiliar in terms of familial, social, cultural and material domains.

In this paper, we have not examined the impact of return visits on settlement and integration in Australia. Yet the notion that transnational activity is a threat to integration and belonging in sites of settlement has been largely discounted by researchers (de Bree, Davids and de Haas 2010; Kivisto 2001; Muggeridge and Doná 2006; Nagel and Staeheli 2008). Indeed, some empirical research indicates that transnational engagement is positively correlated with integration in sites of settlement (Kivisto 2001; Vertovec 2009). In this study, return visits to homelands did not appear to erode belonging to Australia; it is unclear, however, whether return visits support good settlement experience in the longer term. Certainly, these young people continued to actively build long-term futures in Australia following their return visits (Correa-Velez et al. 2010; Nunn et al. 2014; McMichael et al. 2011).

The phenomenon of return visits has been under-researched among young people from refugee backgrounds. In this paper, the accounts of young people from refugee backgrounds highlight the value of local engagement with homelands during return visits. They indicate that situated knowledge and physical encounters with homelands still matter to people in a "modern mobile and globalised world" (Fallov et al. 2013: 468). Belonging to homelands is unsettled by forced displacement and resettlement of refugees and, arguably, young refugees in particular. While not necessarily providing an unambiguous opportunity to belong, return visits provide the possibility for refugee-background young people to develop and negotiate connections to homelands across multiple domains of belonging.

1. South Sudan became an independent State in July 2011. This event occurred following the resettlement of this study's participants, and post the initial data collection (2004) during which cultural identification was sought and recorded. Participants' cultural background and country of birth are those which they themselves provided in 2004. The country terminology 
employed in this paper is that which is used by participants. References to 'Sudan' may refer to what is now 'North Sudan' and/or 'South Sudan'.

\section{ACKNOWLEDGEMENTS}

Thank you to all of the young people who participated in this study. This research project was supported by the Australian Research Council (DP120101579).

\section{REFERENCES}

Al-Ali, N., R. Black and K. Koser (2001) 'The limits of transnationalism: Bosnian and Eritrean refugees in Europe as emerging transnational communities', Ethnic and Racial Studies, 24 (4), 578-600.

Allen, T. and H. Morsink (eds) (1994) When Refugees Go Home, London: James Currey Publishers.

Antonsich, M. (2010) 'Searching for belonging - an analytical framework', Geography Compass, 4 (6), 644-659.

Arowolo, 0.0 (2000) 'Return migration and the problem of reintegration', International Migration, $38(5), 59-82$.

Baldassar, L. (2001) Visits Home: Migration Experiences between Italy and Australia, Melbourne: Melbourne University Press.

Baldassar, L. (2007) 'Transnational Families and Aged Care: The Mobility of Care and the Migrancy of Ageing', Journal of Ethnic and Migration Studies, 33 (2), 275-297.

Barnes, D. (2001) “Resettled refugees' attachment to their original and subsequent homelands: long-term Vietnamese refugees in Australia', Journal of Refugee Studies, 14 (4), 394-411.

Basch, L., N. Glick Schiller and C. Blanc-Szanton (1994) Nations unbound: transnational projects, postcolonial predicaments, and deterritorialized nation-states, Langhorne: Gordon and Breach.

Bascom, J. (2005) 'The long "last step"? Reintegration of repatriates to Eritrea', Journal of Refugee Studies, 18 (2), 165-180.

Binaisa, N. (2011) 'Negotiating 'Belonging' to the Ancestral 'Homeland': Ugandan Refugee Descendants 'Return”, Mobilities, 6 (4), 519-534. 
Black, R. (2002) 'Conceptions of "home" and the political geography of refuge repatriation: between assumption and contested reality in Bosnia-Herzegovina', Applied Geography: An International Review, 22 (2), 123-138

Carruthers, A. (2002) 'The accumulation of national belonging in transnational fields: ways of being at home in Vietnam', Identities: Global Studies in Culture and Power, 9 (4), 423-444.

Cornish F., K. Peltzer and M. MacLachlan (1999) 'Returning Strangers: the children of Malawian refugees come 'home'?', Journal of Refugee Studies, 12 (3), 265-238.

Correa-Velez, I., S. Gifford and A.G. Barnett (2010) 'Longing to Belong: Social Inclusion and Wellbeing among Youth with Refugee Backgrounds in the First Three Years in Melbourne, Australia', Social Science and Medicine, 71 (8), 1399-1408.

Cuny, F. and B. Stein (1990) 'Prospects for and promotion of spontaneous repatriation', in G. Loescher and L. Monahan (eds.) Refugees and International Relations. Oxford: Oxford University Press, 293-312.

De Bree, J., T. Davids and H. de Haas (2010) 'Post-return experiences and transnational belonging of return migrants: a Dutch-Moroccan case study', Global Networks, 10 (4), 489-509.

Duval, D.T. (2004) 'Conceptualising return visits: a transnational perspective', in T. Coles and T. Dallen (eds.) Tourism, Diasporas, and Space, London: Routledge, 50-61.

Duval, D.T. (2003) 'When hosts become guests: return visits and transnational identities in a Commonwealth Eastern Caribbean community', Current Issues in Tourism, 6 (4), 267-308.

Fallov, M., Jørgensen, A. and Knudsen, L. (2013) 'Mobile Forms of Belonging', Mobilities, 8 (4), 467486.

Farwell, M. (2001) "Onward through strength': coping and psychological support among refugee youth returning to Eritrea from Sudan', Journal of Refugee Studies, 14 (1), 43-69.

Fortier, A.M. (2000) Migrant Belongings: Memory, Space, Identity, Oxford: Berg. 
Friedmann, J, (2002) 'Placemaking as project? Habitus and migration in transnational cities', in J. Hillier and E. Rooksby E (eds.) Habitus: A Sense of Place, Aldershot: Ashgate, 299-316.

Giddens, A. (1990) The Consequences of Modernity. Cambridge: Polity Press.

Gifford, S.M., C. Bakopanos, I. Kaplan, and I. Correa-Velez (2007) 'Meaning or Measurement? Researching the Social Contexts of Health and Settlement among Newly Arrived Refugee Youth in Melbourne, Australia', Journal of Refugee Studies, 20 (3): 414-440. 7

Gifford, S.M., Correa-Velez, I. and Sampson, R. (2009) Good Starts for recently arrived youth with refugee backgrounds: Promoting wellbeing in the first three years of settlement in Melbourne, Australia: A research report. Victoria, Australia: La Trobe Refugee Research Centre, La Trobe University Victoria. http://apo.org.au/research/good-starts-recently-arrived-youth-refugeebackgrounds

Gifford, S.M. and Wilding R. (2013) 'Digital Escapes? ICTs, Settlement and Belonging among Karen Youth in Melbourne, Australia', Journal of Refugee Studies, 26 (4), 558-575.

Gustafson, P. (2005) 'International Migration and National Belonging in the Swedish Debate on Dual Citizenship', Acta Sociologica, 48 (1), 5-19.

Jeffery, L. and J. Murison (2011) 'Guest editorial: the temporal, social, spatial and legal dimensions of return and onward migration', Population, Space, Place 17, 131-139.

Hage, G. (1998) White Nation: Fantasies of white supremacy in a multicultural society, Annandale and West Wickham: Pluto Press/Comerford and Miller

Hugo, G. (2011) Economic, Civic and Social Contributions of First and Second Generation Humanitarian Migrants, Canberra: Department of Immigration and Citizenship.

Iaria, V. (2013) 'Post-return transnationalism and the Iraqi Displacement in Syria and Jordan', International Migration Review, 52 (6), 43-56.

Kibria, N. (2002) 'Of blood, belonging, and homeland trips: transnationalism and identity among second-generation Chinese and Korean Americans', in P. Levitt and M.C. Waters (eds.) The Changing Face of Home: The Transnational Lives of the Second Generation, New York: Russell Sage Foundation, 295-311 
King, R., A. Christou and J. Teerling (2011) “We took a bath with the chickens': memories of childhood visits to the homeland by second-generation Greek and Greek Cypriot 'returnees", Global Networks, $11(1), 1-23$.

Kivisto, P. (2001) 'Theorizing transnational immigration: a critical review of current efforts', Ethnic and Racial Studies, 24 (4): 549-77.

Khoo, S. (2012) Key Research Questions for a Longitudinal Survey of Refugees and Other Humanitarian Migrants, Canberra: Australian Demographic and Social Research Institute, The Australian National University.

Kumsa, M.K. (2006) "No! I'm not a refugee!' The poetics of be-longing among young Oromos in Toronto', Journal of Refugee Studies, 19 (2): 231-255.

Leach, N, (2002) 'Belonging: Towards a theory of identification with space', in J. Hillier and E. Rooksby (eds.) Habitus: A Sense of Place, Aldershot: Ashgate, 281-95.

Lee, $\mathrm{H},(2011)$ 'Rethinking transnationalism through the second generation', The Australian Journal of Anthropology, 22 (3), 295-313.

May, V. (2011) 'Self, belonging and social change', Sociology, 45 (3), 363-378

McMichael, C., S.M. Gifford and I. Correa-Velez (2011) 'Negotiating Family, Navigating Resettlement: Family Connectedness amongst Resettled Youth with Refugee Backgrounds Living in Melbourne, Australia', Journal of Youth Studies, 14 (2), 179-95.

McMichael, C., C. Nunn, S. Gifford and I. Correa-Velez (2015) 'Studying Refugee Settlement with Longitudinal Research: Methodological and Ethical Challenges from the Good Starts Study', Journal of Refugee Studies, 28 (2), 238-257.

Muggeridge, H. and G. Doná (2006) 'Back home? Refugees' experiences of their first visit back to their country of origin', Journal of Refugee Studies 19 (4), 416-432.

Nagel, C. R. and L. A. Staeheli (2008) 'Integration and the negotiation of "here" and "there": the case of British Arab activists', Social and Cultural Geography, 9 (4), 415-30. 
Nunn, C., C. McMichael, S.M. Gifford and I. Correa-Velez (2014) "I Came to this Country for a Better Life': Factors Mediating Employment Trajectories among Young People who Migrated to Australia as Refugees During Adolescence', Journal of Youth Studies, 17 (9), 1205-1220.

Nunn, C., McMichael, C., Gifford, S. and Correa-Velez, I. (2016) 'Mobility and security: The perceived benefits of citizenship for resettled young people from refugee backgrounds', Journal of Ethnic and Migration Studies, 42 (3), 382-399.

Oeppen, C. (2013) 'A stranger at 'home': interactions between transnational return visits and integration for Afghan-American professionals', Global Networks, 13 (2), 261-278

Oxfeld, E. and L.D. Long (2004) 'Introduction: an ethnography of return', in L.D. Long and E. Oxfeld (eds.) Coming Home! Refugees, migrants and those who stayed behind, Philadephia: University of Philadelphia Press, 2-15.

Patton, M. (2015) Qualitative Research and Evaluation Methods, Thousand Oaks, California: Sage Publications.

Richardson, S., Stack, S., Moskos, M., Lester, L., Healy, J. et al. 2004. The Changing Settlement Experience of New Migrants; Inter- Wave Comparisons of Cohort 1 and 2 of the LSIA. Canberra: Department of Immigration and Multicultural and Indigenous Affairs.

Rishbeth, C. and M. Powell (2013) 'Place Attachment and Memory: Landscapes of Belonging as Experienced Post-migration', Landscape Research, 38 (2), 160-178.

Rousseau, C., M. Morales and P. Foxen, P (2001) 'Going home: giving voice to memory of strategies of young Mayan refugees who returned to Guatemala as a community', Culture, Medicine and Psychiatry, 25, 135-168.

Sagmo, T. (2014) 'Return visits as a marker of differentiation in the social field', Mobilities. DOI: $10.1080 / 17450101.2014 .891869$

Saito, M. and Kantor, P. (2010) 'From Mohajer to Hamwatan: the reintegration experiences of second generation Afghans returning from Pakistan and Iran', in D. Chatty \& B. Finlayson (eds.) 
Dispossession and Displacement: Forced Migration in the Middle East and North Africa, Oxford: Oxford University Press, 123-145.

Skey, M. (2010) “A sense of where you belong in the world': national belonging, ontological security and the status of the ethnic majority in England', Nations and Nationalism 16 (4), 715-733.

Tilley, C. (1994) A Phenomenology of Landscape: Places, Paths and Monuments, Oxford: Berg.

Vathi, Z. and R. King (2011) 'Return Visits of the Young Albanian Second Generation in Europe: Contrasting Themes and Comparative Host-Country Perspectives', Mobilities, 6 (4), 503-518.

Vertovec, S. (2009) Transnationalism, Abingdon: Routledge.

Wimmer, A. and N. Glick Schiller (2002) 'Methodological nationalism and beyond: nation-state building, migration and the social sciences', Global Networks, 2 (4), 301-334.

Yuval-Davis, N. (2006) 'Belonging and the politics of belonging', Patterns of Prejudice, 40 (3), 197214.

Yuval-Davis, N. (2011) 'Introduction: framing the questions', in The politics of belonging: intersectional contestations, London: Sage Publications, 1-45. 